\title{
Evaluation of drug interaction potential of Labisia pumila (Kacip Fatimah) and its constituents
}

\author{
Vamshi K. Manda ${ }^{1}$, Olivia R. Dale ${ }^{1}$, Charles Awortwe ${ }^{2}$, Zulfiqar Ali ${ }^{1}$, Ikhlas A. Khan ${ }^{1,3}$, Larry A. Walker ${ }^{1,4}$ \\ and Shabana I. Khan ${ }^{1,3}$ *
}

\author{
' National Center for Natural Products Research, School of Pharmacy, The University of Mississippi, Oxford, MS, USA \\ ${ }^{2}$ Division of Clinical Pharmacology, University of Stellenbosch, Cape Town, South Africa \\ ${ }^{3}$ Division of Pharmacognosy, Department of Biomolecular Sciences, School of Pharmacy, The University of Mississippi, Oxford, MS, USA
}

${ }^{4}$ Division of Pharmacology, Department of Biomolecular Sciences, School of Pharmacy, The University of Mississippi, Oxford, MS, USA

\section{Edited by:}

Emilio Clementi, University of Milano, Italy

\section{Reviewed by:}

Paavo Honkakoski, University of

Eastern Finland, Finland

Oliver Burk, Dr. Margarete

Fischer-Bosch-Institute of Clinical

Pharmacology, Germany

Paul Cos, Antwerp University,

Belgium

\section{*Correspondence:}

Shabana I. Khan, National Center for Natural Products Research, School of Pharmacy, The University of

Mississippi, Oxford, MS 38677, USA

e-mail:skhan@olemiss.edu
Labisia pumila (Kacip Fatimah) is a popular herb in Malaysia that has been traditionally used in a number of women's health applications such as to improve libido, relieve postmenopausal symptoms, and to facilitate or hasten delivery in childbirth. In addition, the constituents of this plant have been reported to possess anticancer, antioxidant, and antiinflammatory properties. Clinical studies have indicated that cytochrome P450s (CYPs), P-glycoprotein (P-gp), and Pregnane $X$ receptor (PXR) are the three main modulators of drug-drug interactions which alter the absorption, distribution, and metabolism of drugs. Given the widespread use of Kacip Fatimah in dietary supplements, the current study focuses on determining the potential of its constituents to affect the activities of CYPs, Pgp, or PXR using in vitro assays which may provide useful information toward the risk of herb-drug interaction with concomitantly used drugs. Six compounds isolated from the roots of L. pumila (2 saponins and 4 alkyl phenols) were tested, in addition to the methanolic extract. The extract of $L$. pumila showed a significant time dependent inhibition (TDI) of CYP3A4, reversible inhibition of CYP2C9 and 2C19 and a weak inhibition of $1 \mathrm{~A} 2$ and 2D6 as well as an inhibition of P-gp and rifampicin-induced PXR activation. The alkyl phenols inhibited CYP3A4 (TDI), CYP2C9, and 2C19 (reversible) while saponins inhibited P-gp and PXR. In conclusion, L. pumila and its constituents showed significant modulation of all three regulatory proteins (CYPs, P-gp, and PXR) suggesting a potential to alter the pharmacokinetic and pharmacodynamic properties of conventional drugs if used concomitantly.

\section{Keywords: Labisia pumila, Myrsinaceae, herb-drug interactions, PXR, CYP450 enzymes, P-gp}

\section{INTRODUCTION}

Labisia pumila (Blume) Fern.-Vill., locally termed as Kacip Fatimah (KF), is a popular herb in South East Asian countries. It belongs to the Myrsinaceae family. Recently it has been identified as one of the top five herbs used in Malaysia for treating variety of ailments (Karimi et al., 2013). Traditionally, KF is mainly used in a wide spectrum of women's health related issues; the effects are presumed as attributable to the presence of estrogenlike compounds. KF is often taken during and after pregnancy for its beneficial effects on uterine function and delivery. The primary route of administration of KF is oral, whereby the leaves, roots, or whole plant are boiled in water and consumed. Additionally, it is sold commercially in the form of herbal tea, powder, capsules, and tablets in many countries (Abdul Kadir et al., 2012). Clinical studies have also suggested the usefulness of KF extract in treating postmenopausal symptoms (Abdul Kadir et al., 2012) with

Abbreviations: CYPs, Cytochrome P450 enzymes; FDA, Food and Drug Administration; HepG2, human hepatocellular carcinoma; hMDR1-MDCK-II, human multidrug resistance-1-transfected Madin-Darby canine kidney; MDCK-II, MadinDarby canine kidney; Ly, Lucifer yellow; P-gp, P-glycoprotein; PXR, Pregnane X receptor; TDI, Time dependent inhibition. no acute toxicity (Singh et al., 2009). Furthermore, the extract and constituents of KF have been shown to possess anticancer, antioxidant, anti-osteoporosis, and anti-inflammatory properties (Nadia et al., 2012; Fathilah et al., 2013).

Due to the increasing popularity and wide spread use of herbal supplements throughout the world, there is a potential risk of herb-drug interactions when these supplements are taken in combination with conventional drugs, as there is often limited standardization of dose of herbal supplements taken. This is evident by the increasing reports of clinical cases of toxicity caused by herb-drug interactions (Chen et al., 2011, 2012). Early identification of drug interaction potential of herbal supplements and their constituents will aid in lowering the risk of herb-drug interactions. It is widely documented that CYPs, P-gp, and PXR are the three main modulators of drug-drug interactions as these are involved in affecting the pharmacokinetic and pharmacodynamic properties of xenobiotics (Alissa, 2014). Despite the use of KF as a herbal medicine, limited studies exist in literature for its drug interaction potential. A recent study has indicated that different extracts of L. pumila show potent inhibition of CYPs, specifically CYP2C isoforms (Pan 


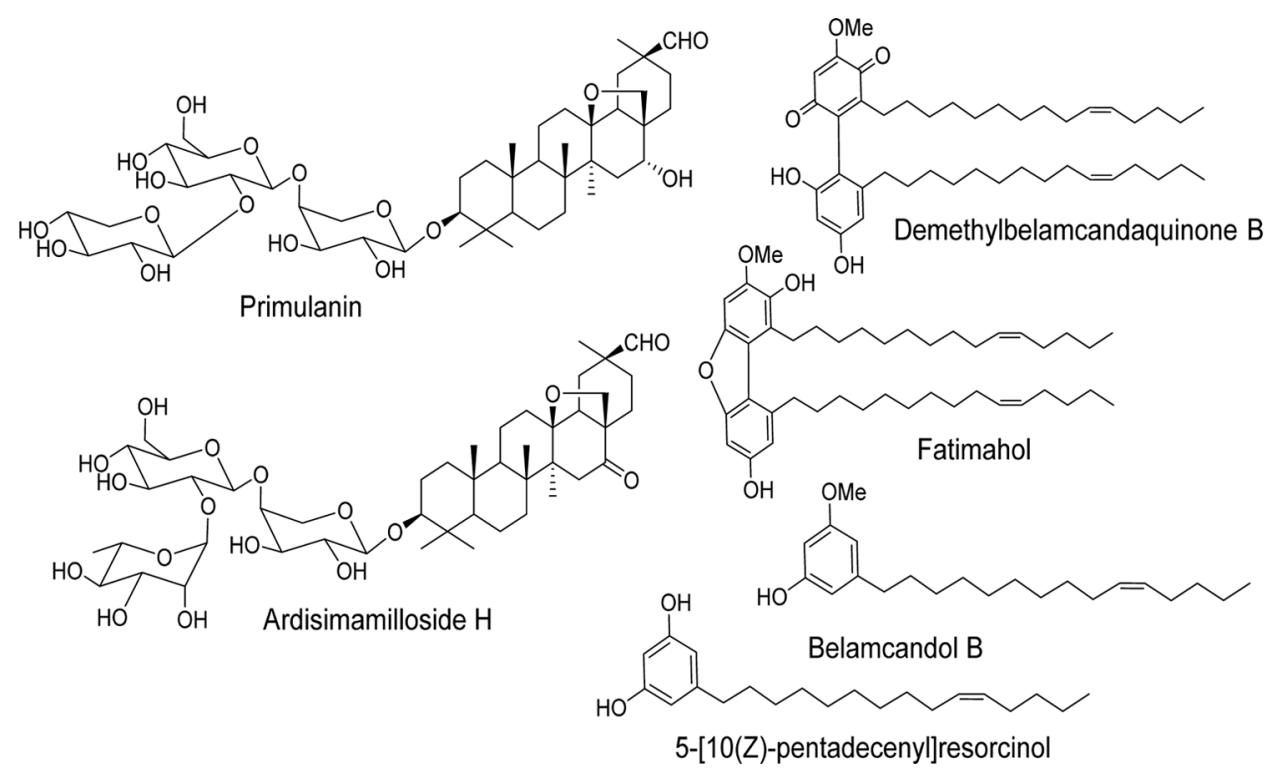

FIGURE 1 | Chemical structures of two saponins and four alkyl phenols isolated from the roots of Labisia pumila.

et al., 2012). However, there are no studies identifying the chemical constituents of KF responsible for CYP inhibition. As part of our phytochemical studies on medicinal plants, several constituents have been isolated from the roots of L. pumila; these belong to various chemical classes, including saponins, alkyl phenols, cerebroside, glycerogalactolipids, and lipids (Ali and Khan, 2011).

In the extension of these studies, the current investigation focuses on determining the potential of KF methanolic extract and its constituents to affect the activities of major drug metabolizing enzymes (CYP 3A4, 2D6, 1A2, 2C9, and 2C19), P-gp, and PXR using in vitro assays which may provide useful information toward the risk of herb-drug interactions with concomitantly used drugs. The inhibition of CYP 3A4, 2D6, 1A2, 2C9, and 2C19 was determined by employing C-DNA baculovirus expressed recombinant enzymes and specific fluorescent substrates. The inhibition of P-gp was determined in hMDR1-MDCK-II (MadinDarby canine kidney) and MDCK-II cells by using two widely used substrates calcein-AM and digoxin. Modulation of PXR activity was monitored through a reporter gene assay in HepG2 cells transfected with PXR plasmid DNA and a luciferase reporter plasmid PCR5. Additionally, we used FDA guided assumptions (Zhang etal., 2009) to predict the likelihood of the KF extract and its constituents to cause herb drug interactions (HDI) in vivo.

\section{MATERIALS AND METHODS}

Madin-Darby canine kidney-II (parental) and hMDR1-MDCKII (transfected) cell lines were a gift from Dr. Gottesman (NIH, Bethesda, USA). Dulbecco's Modified Eagle Medium (DMEM), Minimal Essential Medium (MEM), Hanks balanced salt solution (HBSS), HEPES, Trypsin EDTA, Penicillinstreptomycin, and Sodium Pyruvate were from GIBCO BRL
(Invitrogen Corp., Grand Island, NY, USA). Fetal bovine serum (FBS) was from Hyclone Lab Inc. (Logan, UT, USA). CYP1A2/CEC, CYP2C9/MFC, CYP3A4/BQ, CYP2C19/CEC, and CYP2D6/AMMC high throughput inhibitor screening kits were from BD Gentest (Woburn, MA, USA). Transwell plates (12 mm diameter, $0.4 \mu \mathrm{M}$ pore size) were from Costar Corp. (Cambridge, MA, USA). All other chemicals were from Sigma Chem. Co., (St. Louis, MO, USA). Radio labeled digoxin $\left[{ }^{3} \mathrm{H}\right.$-digoxin, $0.25 \mathrm{mCi} / 0.25 \mathrm{ml}$ ] was from Perkin Elmer Life Sciences (Waltham, MA, USA). Troleandomycin was from Santa Cruz Biotechnology, Inc. (Dallas, TX, USA). Preparation of L. pumila methanolic extract and isolation of its constituents used in the current study were described in our previous study (Ali and Khan, 2011).

\section{CULTURE OF hMDR1-MDCK-II, MDCK-II AND HepG2 CELLS}

Parental and transfected MDCK-II cells were grown in DMEM supplemented with 10\% FBS, 1\% non-essential amino acids, 1\% L-glutamine, $100 \mathrm{U} / \mathrm{ml}$ penicillin-G, and $100 \mu \mathrm{g} / \mathrm{ml}$ streptomycin at $37^{\circ} \mathrm{C}, 95 \%$ relative humidity, and $5 \% \mathrm{CO}_{2}$. Cells were seeded at a density of 65,000 cells/well $(0.5 \mathrm{~mL})$ on the apical side of a 12 -well Transwell plate and $1.5 \mathrm{ml}$ of medium was added to the basolateral side. HepG2 cells were grown in DMEM/F12 medium supplemented with $10 \% \mathrm{FBS}, 2.4 \mathrm{~g} / \mathrm{L}$ sodium bicarbonate, $100 \mathrm{U} / \mathrm{ml}$ penicillin-G, and $100 \mu \mathrm{g} / \mathrm{ml}$ streptomycin at $37^{\circ} \mathrm{C}, 95 \%$ relative humidity, and $5 \% \mathrm{CO}_{2}$.

\section{ASSAYS FOR REVERSIBLE INHIBITION (CO-INCUBATION ASSAY) AND TIME DEPENDENT INHIBITION (PRE-INCUBATION ASSAY) OF CYPS}

The assay for reversible inhibition was conducted in a total volume of $200 \mu \mathrm{L}$ in 96-well microplates. The assay conditions, enzyme and substrate concentrations were similar as reported earlier (Crespi et al., 1997; Manda et al., 2013). Test samples or 


\section{A}

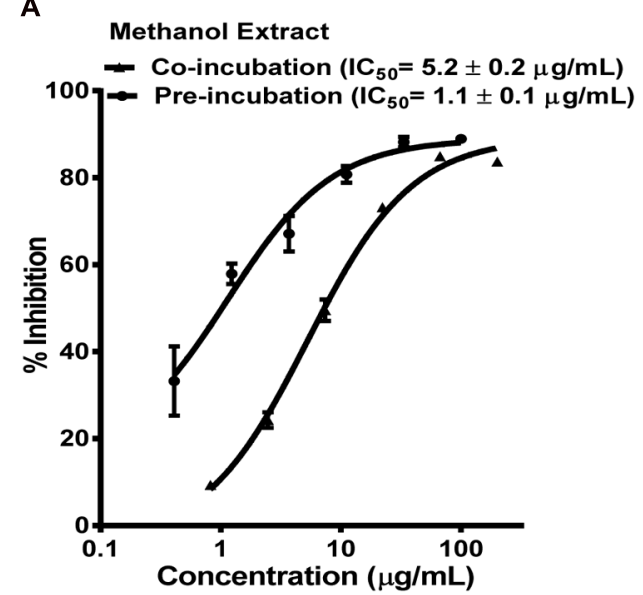

C

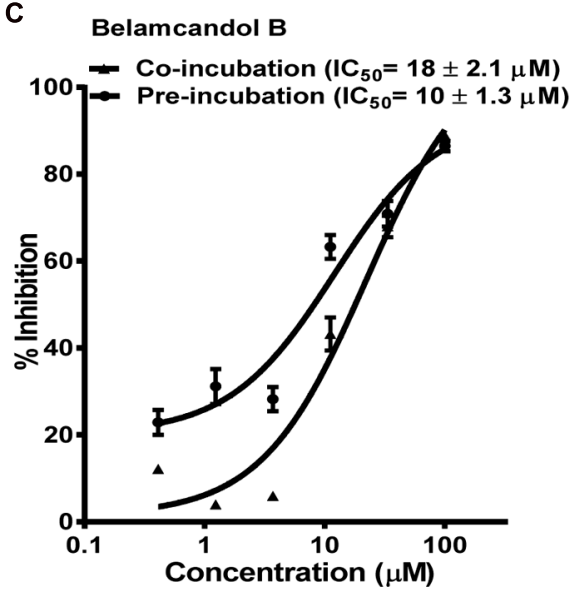

E

Fatimahol

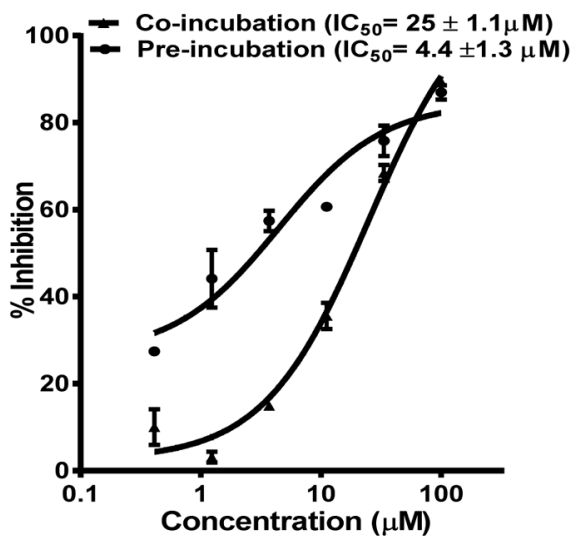

B

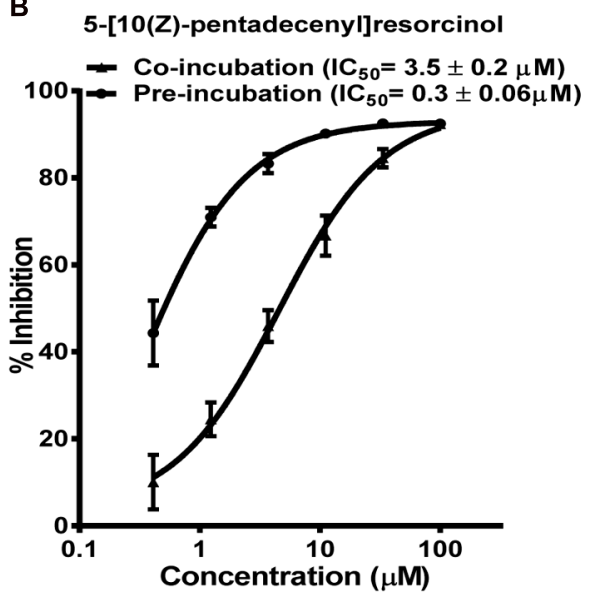

D

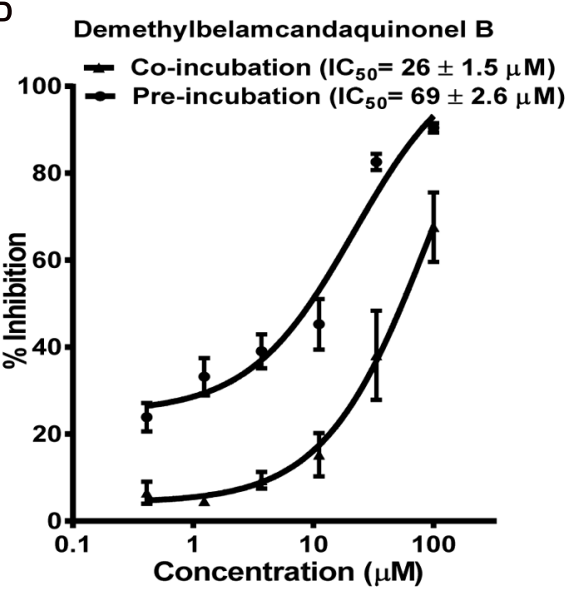

FIGURE 2 | Dose response profiles of reversible and time dependent inhibition (TDI) of CYP3A4 enzyme by Labisia pumila root extract (A) and its alkyl phenolic constituents (B-E). The data are represented as mean \pm SD of 3 independent experiments ( $n=2$ in each experiment).

positive controls were serially diluted in a solution $(100 \mu \mathrm{L})$ of cofactors mix, control protein $(0.05 \mathrm{mg}$ of protein $/ \mathrm{mL})$, and $\mathrm{G}$ 6-PDH to achieve six concentrations $(100-0.4 \mu \mathrm{M}$ or $\mu \mathrm{g} / \mathrm{mL})$. Initial readings were taken to record any inherent fluorescence and the plates were incubated at $37^{\circ} \mathrm{C}$ for $10 \mathrm{~min}$. Reaction was initiated by the addition of enzyme substrate mixture $(100 \mu \mathrm{L})$ followed by incubation for 15,30 , or $45 \mathrm{~min}$. The reaction was terminated by the addition of $75 \mu \mathrm{L}$ of ice cold acetonitrile/0.5 M Tris base (80:20). Fluorescence was measured on Spectramax M5 plate reader (Molecular Devices, Sunnyvale, CA, USA) at specified excitation and emission wavelengths for each substrate. $\mathrm{IC}_{50}$ values (co-incubation assay) were obtained from 

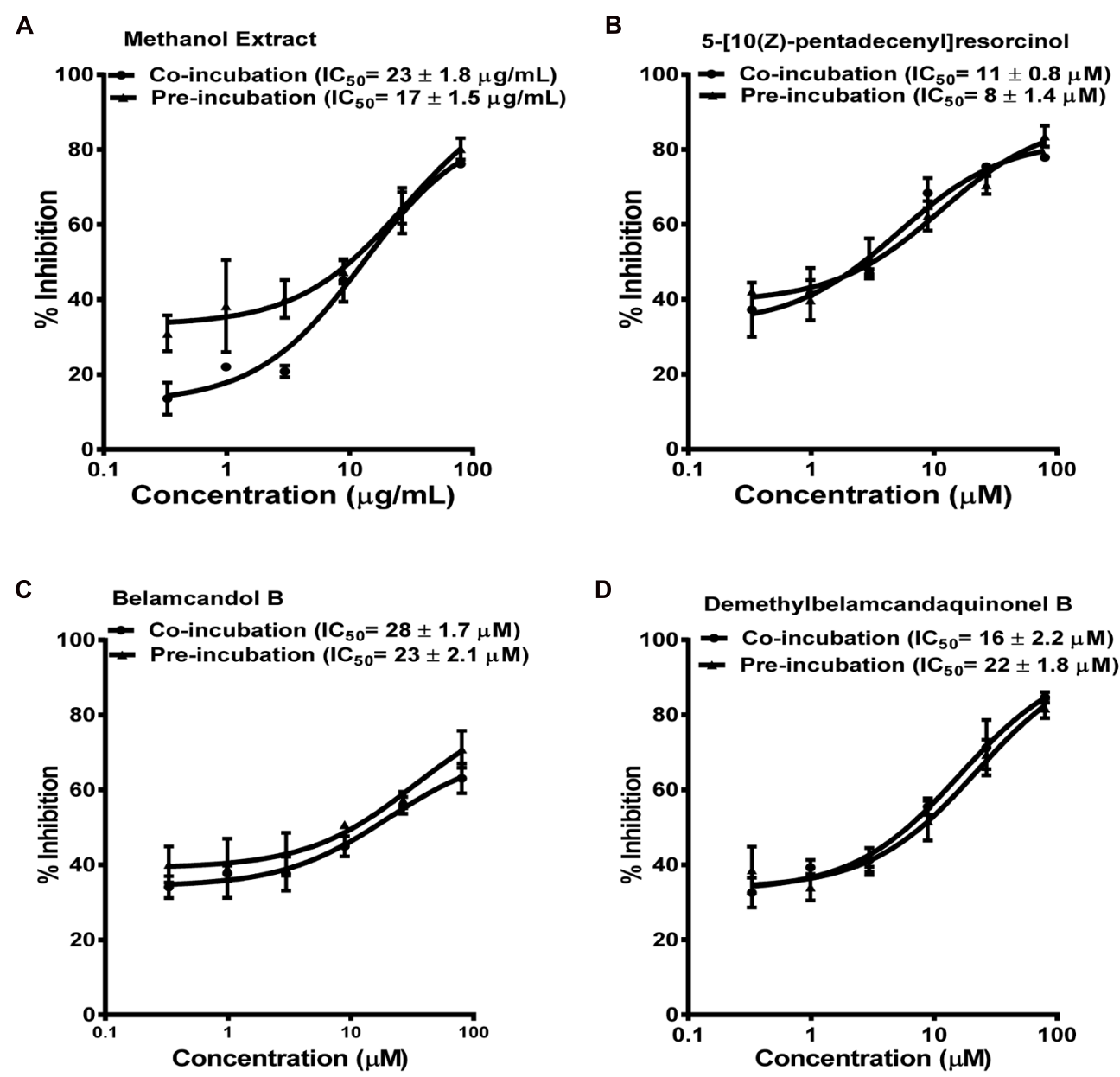

E

Fatimahol

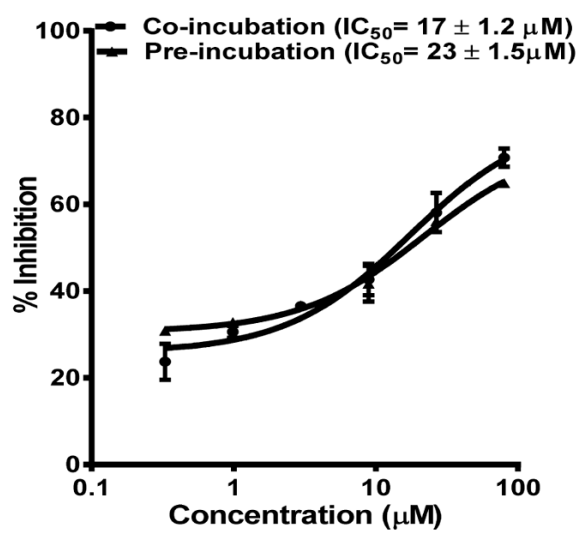

FIGURE 3 | Dose response profiles of reversible and TDI of CYP2C9 enzyme by Labisia pumila root extract (A) and its alkyl phenolic constituents (B-E). The data are represented as mean \pm SD of 3 independent experiments ( $n=2$ in each experiment).

concentration-response curves generated by plotting concentration versus \% inhibition.

Time dependent inhibition (TDI) of CYPs was measured as described earlier by Sekiguchi et al. (2009). The reaction mixture (180-190 $\mu \mathrm{L})$, consisting of test sample, recombinant enzyme, control protein $(0.05 \mathrm{mg}$ of protein/mL), cofactor mix, G-6-PDH, and $50 \mathrm{mM}$ potassium phosphate buffer $(\mathrm{pH} 7.4$ ) was pre-incubated for $30 \mathrm{~min}$ followed by addition of respective fluorescent substrates $(10-20 \mu \mathrm{L})$ and further incubation for 15 (CYP1A2), 30 (CYP3A4), or 45 (CYP 2C9 and 2C19) 
A

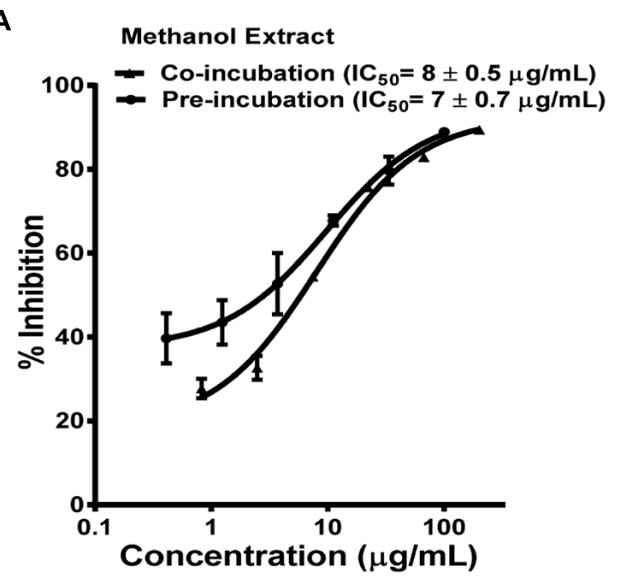

C

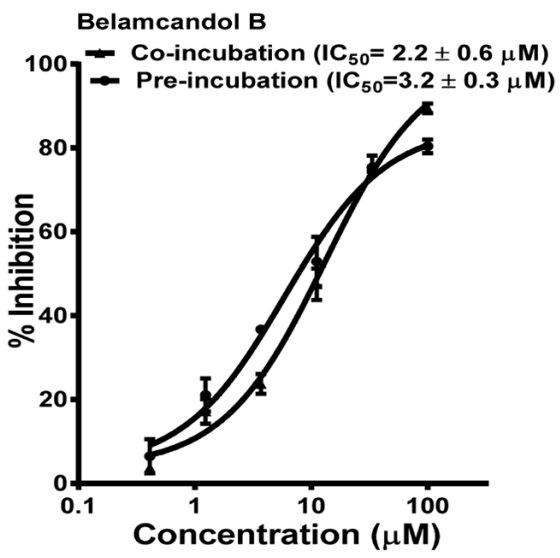

E

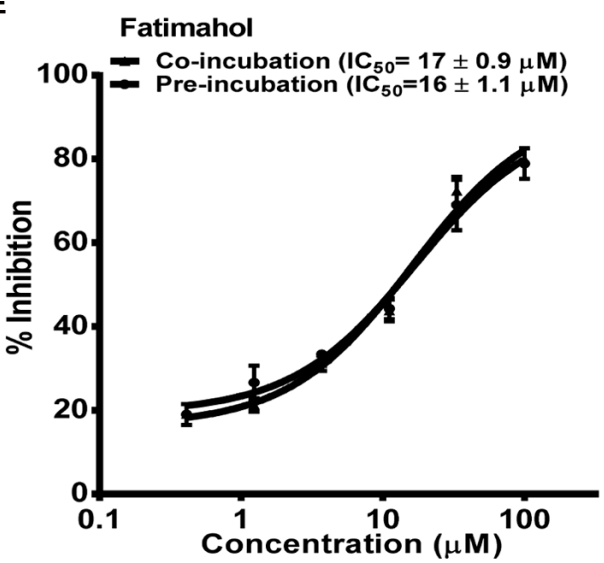

B

5-[10(Z)-pentadecenyl]resorcinol

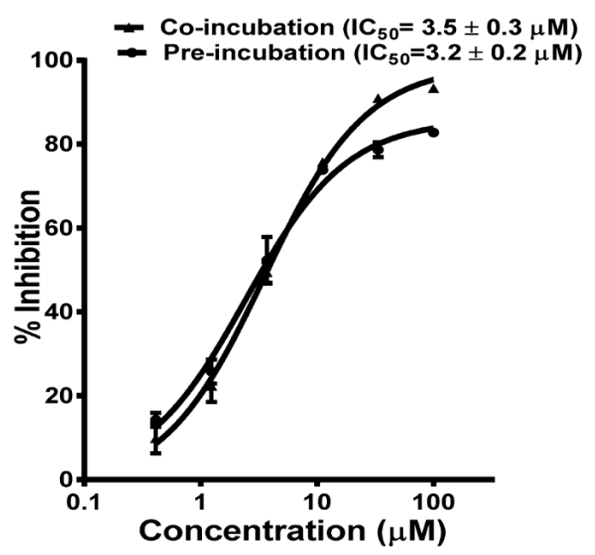

D

Demethylbelamcandaquinonel B

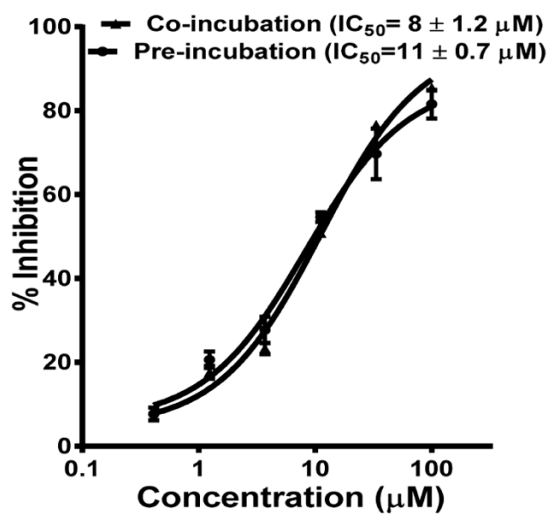

FIGURE 4 | Dose response profiles of reversible and TDI of CYP2C19 enzyme by Labisia pumila root extract (A) and its alkyl phenolic constituents (B-E). The data are represented as mean \pm SD of 3 independent experiments ( $n=2$ in each experiment).

min. The reaction was terminated by addition of $75 \mu \mathrm{L}$ of ice cold acetonitrile/0.5 M Tris base (80:20) and fluorescence was measured as above. $\mathrm{IC}_{50}$ values (pre-incubation assay) were obtained as above. The shift in the concentration-response curve was calculated as the ratio of $\mathrm{IC}_{50}$ (co-incubation)/ $\mathrm{IC}_{50}$ (pre-incubation).

\section{ASSAY FOR PXR MODULATION}

The pSG5-hPXR expression vector was provided generously by Dr. Steven Kliewer (University of Texas Southwestern Medical Center, Dallas, TX, USA; Lehmann et al., 1998) and the reporter plasmid CYP3A4-PXR response element (PXRE)-LUC (containing the proximal 0/-362 and distal 7208/7797 PXRE regions fused 
Table 1 | IC 50 of CYP3A4 inhibition by Labisia pumila methanol extract and its isolated constituents.

\begin{tabular}{llll}
\hline & & CYP3A4 & \\
\cline { 2 - 4 } Extract/compound & $\mathbf{I C}_{\mathbf{5 0}}$ ( $\boldsymbol{\mu} \mathbf{M}$ ) Co-incubation & IC $_{\mathbf{5 0}}$ ( $\boldsymbol{\mu}$ M) Pre-incubation & IC $_{\mathbf{5 0}}$ Shift (fold) \\
\hline Methanol extract $(\mu \mathrm{g} / \mathrm{mL})$ & $5.2 \pm 0.2$ & $1.1 \pm 0.1$ & 4.7 \\
5-[10(Z)-pentadecenyl]resorcinol & $4.1 \pm 0.2$ & $0.3 \pm 0.06$ & 13.6 \\
Belamcandol B & $18 \pm 2.1$ & $10 \pm 1.3$ & 1.8 \\
Demethylbelamcandaquinone B & $69 \pm 2.6$ & $26 \pm 1.5$ & 2.6 \\
Fatimahol & $25 \pm 1.1$ & $4.4 \pm 1.3$ & 5.6 \\
Primulanin & $\mathrm{NA}$ & $\mathrm{NA}$ & - \\
Ardisimamilloside H & $\mathrm{NA}$ & $\mathrm{NA}$ & - \\
Ketoconazole & 0.04 & 0.05 & 0.8 \\
Troleandomycin & $1.5 \pm 0.1$ & $0.44 \pm 0.06$ & 3.4 \\
\hline
\end{tabular}

The data are represented as mean $\pm S D$ of 3 independent experiments ( $n=2$ in each experiment). NT $=$ Not Tested.

upstream of luciferase; Goodwin et al., 1999) was a kind gift from Dr. Christopher Liddle (University of Sydney, Westmead, NSW, Australia). The modulation of PXR activity by test samples was determined in HepG2 cells transiently transfected with pSG5-PXR $(25 \mu \mathrm{g})$ and PCR5 plasmid DNA $(25 \mu \mathrm{g})$ by electroporation at $180 \mathrm{~V}, 1$ pulse for $70 \mathrm{msec}$. The cells were plated in 96-well plates at a density of 50,000 cells per well. After $24 \mathrm{~h}$, test samples and drug controls were added at various concentrations. After additional 24 hour incubation, the media was aspirated and $40 \mu \mathrm{L}$ of luciferase reagent (Promega Corporation, Madison, WI, USA) was added to each well and luminescence was measured on Spectramax M5 plate reader (Molecular Devices, Sunnyvale, CA, USA). The fold induction in luciferase activity in the treated cells was calculated in comparison to vehicle treated cells. The cytotoxicity of test samples toward HepG2 cells was also determined by measuring the cell viability using the CellTiter $96 \mathrm{AQ}_{\text {ueous }}$ One Solution Cell Proliferation Assay (MTS) as described earlier (Manda et al., 2013).

\section{ASSAY FOR P-gp INHIBITION BY CALCEIN-AM UPTAKE IN PARENTAL AND TRANSFECTED MDCK-II CELLS}

The assay was performed as described previously (Rautio et al., 2006). Cells were seeded in 96-well plates at 70,000 cells/well in $200 \mu \mathrm{L}$ of culture medium. The medium was changed at $24 \mathrm{~h}$ after seeding and the assay was performed $48 \mathrm{~h}$ later. Test samples at various concentrations and positive control (verapamil 100-0.4 $\mu \mathrm{M}$ ) were added to the cells in $50 \mu \mathrm{L}$ of transport buffer and incubated at $37^{\circ} \mathrm{C}$ for $10 \mathrm{~min}$. Calcein-AM $(1 \mu \mathrm{M})$, a fluorescent P-gp substrate) was added and the plates were immediately placed on Spectramax and fluorescence was read up to $1 \mathrm{~h}$ at 15 -min intervals at excitation and emission wavelengths of 485 and $530 \mathrm{~nm}$, respectively. The \% increase in calcein-AM uptake was calculated as described earlier (Liu et al., 2008; Manda et al., 2014).

The $\mathrm{EC}_{50}$ value, defined as the concentration that caused an increase of $50 \%$ in calcein-AM uptake, was obtained from dose curves generated by plotting \% increase in calcein-AM uptake versus log concentration using GraphPad Prism.

\section{ASSAY FOR P-gp INHIBITION BY ${ }^{3}$ H-DIGOXIN UPTAKE IN hMDR1-MDCK-II CELLS}

The assay conditions were similar as described earlier (Rautio et al., 2006) with some modifications. The cells were seeded at a density of 120,000 cells/well in 12-well Transwell plates and cultured for 3 days. TEER values were in the range of 500-800 $\Omega \mathrm{cm}^{2}$. Cells were washed with warm HBSS buffer supplemented with $10 \mathrm{mM}$ HEPES ( $\mathrm{pH} 7.4)$ and pre-incubated with $0.5 \mathrm{~mL}$ of buffer containing test samples (six concentrations) on the apical side and $1.5 \mathrm{~mL}$ of buffer on the basolateral side for $30 \mathrm{~min}\left(37^{\circ} \mathrm{C}, 5 \% \mathrm{CO}_{2}\right.$, and $95 \%$ relative humidity). After incubation, buffer was removed from the basolateral side and replaced with $1.5 \mathrm{~mL}$ of buffer containing ${ }^{3} \mathrm{H}$-digoxin $(40 \mathrm{nM})$, test compounds or standard drugs $(25 \mu \mathrm{M})$, and incubated further for $2 \mathrm{~h}$. Aliquots of $25 \mu \mathrm{L}$ were taken out from the apical side, mixed with $100 \mu \mathrm{L}$ of scintillant (Microscint TM-40, PerkinElmer) and radioactive counts were measured on a TopCount microplate scintillation counter (PerkinElmer, Waltham, MA, USA) in CPM mode. The monolayer integrity was monitored by measuring the permeability of Ly (a fluorescent marker of passive paracellular diffusion) as described earlier (Manda et al., 2013).

The inhibition of the basolateral to apical $(\mathrm{B}-\mathrm{A})$ transport of digoxin by test samples was calculated compared to the vehicle control. The $\mathrm{IC}_{50}$ value, defined as the concentration that caused an inhibition of $50 \%$ in digoxin transport, was obtained from dose curves generated by plotting \% inhibition versus log concentration using GraphPad Prism.

\section{PREDICTION OF IN VIVO HDI FROM IN VITRO RESULTS}

All assumptions to predict the HDI potential of KF methanolic extract and its constituents were according to previously published report (Awortwe et al., 2014). The \% yield was calculated from the amounts extracted from the KF roots (Ali and Khan, 2011). The human GIT volume is $250 \mathrm{~mL}$ and plasma volume is about $3 \mathrm{~L}$. The commonly used maximum dose of KF extract capsules is $560 \mathrm{mg}$ per day (Abdul Kadir et al., 2012) and accordingly we estimated 
A

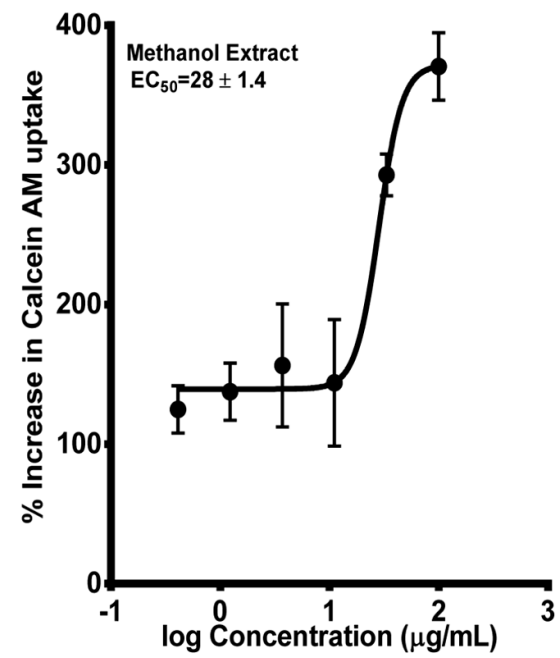

C

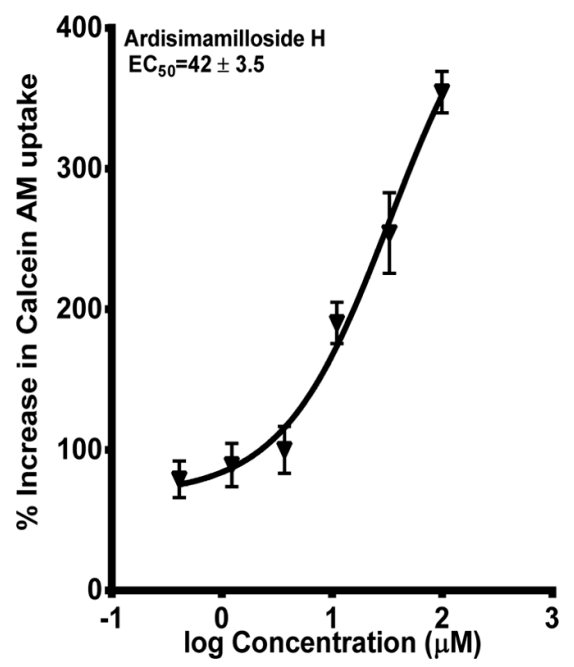

FIGURE 5 | Dose-response curves of P-gp inhibition by methanol extract of Labisia pumila roots (A), its two saponin constituents (B-C) and positive control verapamil (D), determined by calculating the percent uptake of calcein AM into hMDR1-MDCKII cells.

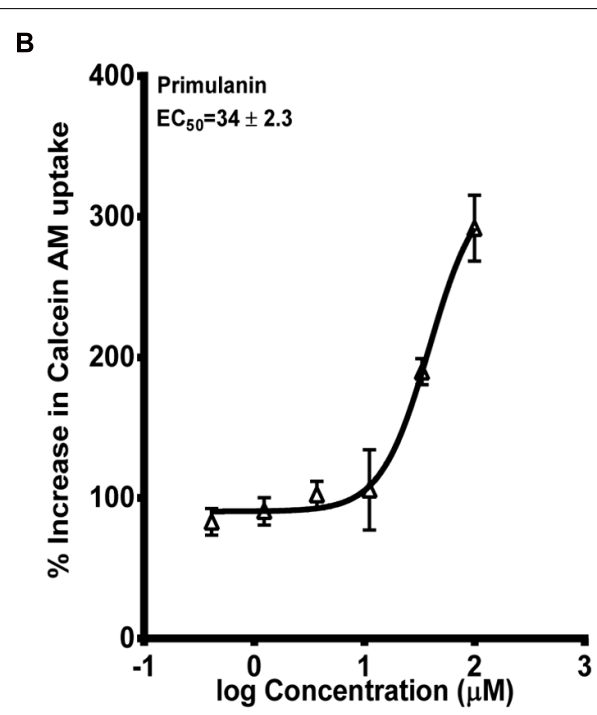

D

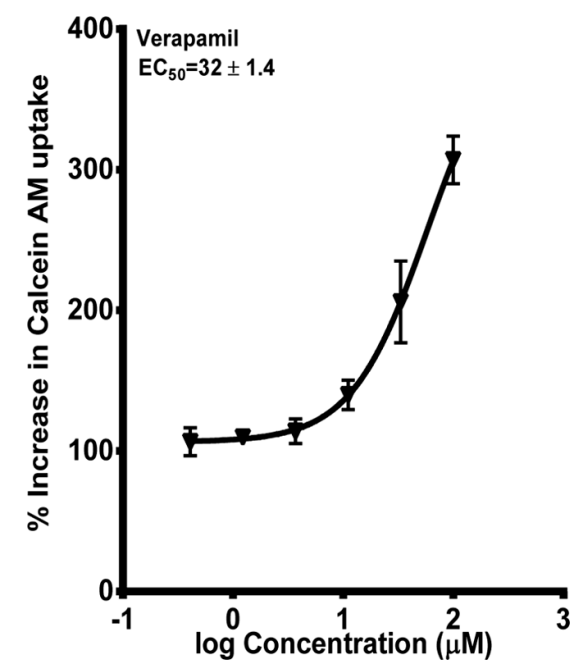

Equations used in evaluating $\mathrm{EC}_{50}$ and \% increase in uptake of calcein-AM were described in "Materials and Methods" section. The data are represented as mean \pm SD of 3 independent experiments ( $n=2$ in each experiment). the concentration per dose, GIT, and plasma concentrations of extract and its constituents. We then compared the in vitro $\mathrm{IC}_{50}$ values obtained from recombinant CYPs with estimated GIT and plasma concentrations. If the $\mathrm{IC}_{50}$ values were lower than the GIT or plasma concentration, then the test compound or extract is likely to cause HDI in vivo. The prediction was not done for two saponins as they did not show any inhibition toward CYPs tested.

\section{STATISTICAL METHODS}

All values are represented as mean $\pm \mathrm{SD}(n=3)$. The data were analyzed by one way ANOVA, followed by Dunnett's multiple comparison tests using GraphPad Prism Version 5, (San Diego, CA, USA). $P<0.05$ was considered to be statistically significant.

\section{RESULTS}

\section{REVERSIBLE INHIBITION AND TDI OF CYPs}

The two major classes of compounds isolated from the roots of KF are alkyl phenols and triterpene glycosides (saponins) as reported earlier (Ali and Khan, 2011). We have determined the effect of methanolic extract of $\mathrm{KF}$ and its six constituents (4 alkyl phenols and 2 saponins, Figure 1 on major CYPs using specific fluorescent substrates and recombinant enzymes.

The methanolic extract and alkyl phenolic compounds showed dose dependent inhibition of CYP3A4, 2C9, and 2C19 (Figures 2-4) while saponins did not affect the activity of these enzymes. Out of the alky phenols, 5-[10(Z)-pentadecenyl]resorcinol was effective in inhibiting CYP3A4 and 2C9 with $\mathrm{IC}_{50}$ 


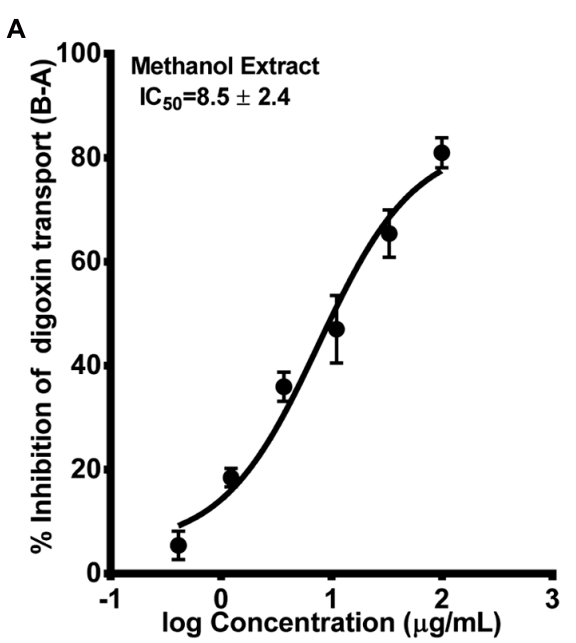

C

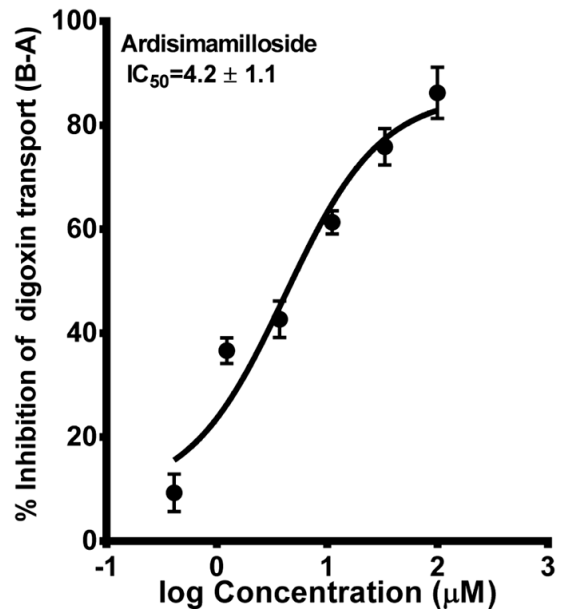

B

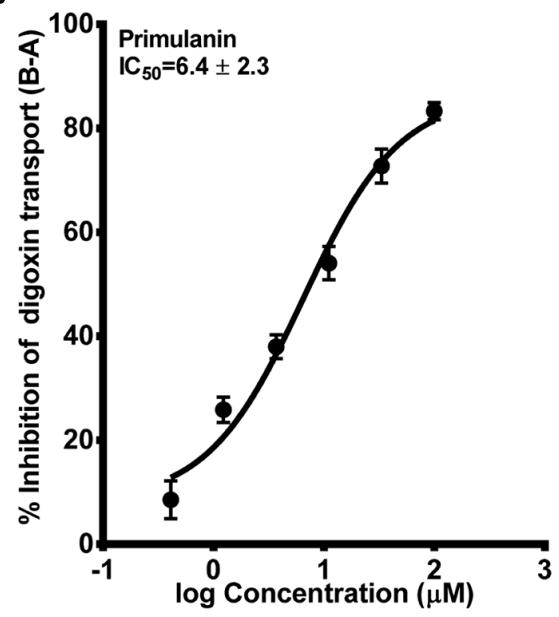

D

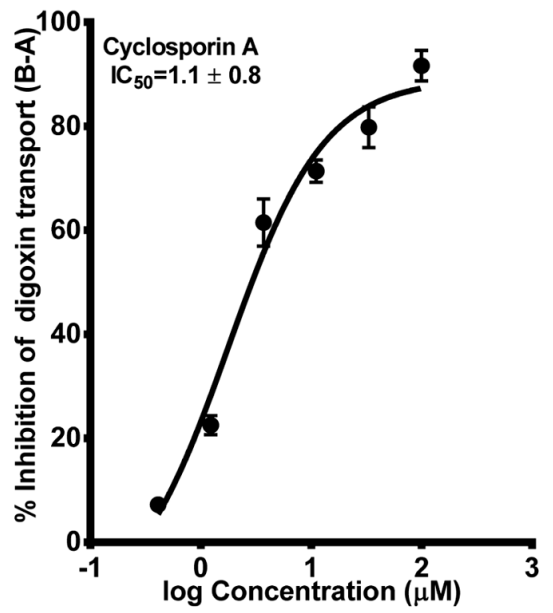

FIGURE 6 | Dose-response curves of P-gp inhibition by methanol extract (A) of Labisia pumila roots, its two saponin constituents (B-C) and positive control cyclosporin A (D), determined by calculating the basolateral to apical transport $(\%)$ of ${ }^{3} \mathrm{H}$-digoxin across hMDR1-MDCKII cell monolayers. The data are represented as mean \pm SD of 3 independent experiments ( $n=1$ in each experiment).

values of $4.1 \pm 0.2$ and $11 \pm 0.8 \mu \mathrm{M}$, respectively, while belamcandol B inhibited CYP2C19 with an $\mathrm{IC}_{50}$ value of $2.2 \pm 0.6 \mu \mathrm{M}$.

Based on these results, we further tested the TDI potential of extract and selected constituents toward CYP3A4, 2C9, and 2C19. The test samples were pre-incubated for $30 \mathrm{~min}$ with the co-factors, control protein, and specific enzymes before substrates were added. $\mathrm{IC}_{50}$ shift was determined as described in the Materials and Methods. Compounds which showed $\mathrm{IC}_{50}$ shift ratio of greater than 1.5 were considered to have potential to exhibit TDI. Based on these criteria, no timedependent inhibition was observed with recombinant CYP2C9 and 2C19 enzymes by the test compounds or the methanol extract. The dose curves were identical from co-incubation and pre-incubation experiments (Figures 3 and 4 . The $\mathrm{IC}_{50}$ shift fold ratios of the control drugs (tranylcypromine, Table 1) were similar to the published literature values (Naritomi et al., 2004). In contrast, the methanol extract as well as the four alkyl phenols showed a very potent TDI of CYP3A4 with the dose curves shifted significantly to the left, as shown in Figure 2. The $\mathrm{IC}_{50}$ shift fold ratio for 5-[10(Z)-pentadecenyl]resorcinol, fatimahol, and methanol extract was 13.6, 5.6, and 4.7, respectively, (Table 1 suggesting a very strong potential for TDI of CYP3A4 by these agents. The positive control for TDI, troleandomycin, showed an $\mathrm{IC}_{50}$ shift fold ratio of 3.4 Table 1 which is in accordance to the previous report (Sekiguchi etal., 2009). Further, the dose response curves clearly indicate a significant increase in \% inhibition when the extract or the compounds were preincubated with CYP3A4 enzyme (Figure 2).

\section{P-gp INHIBITION}

Next, we determined the inhibition of P-gp by the extract of L. pumila and the constituents by using the two widely used probes calcein-AM and digoxin (Rautio et al., 2006). Calcein-AM 


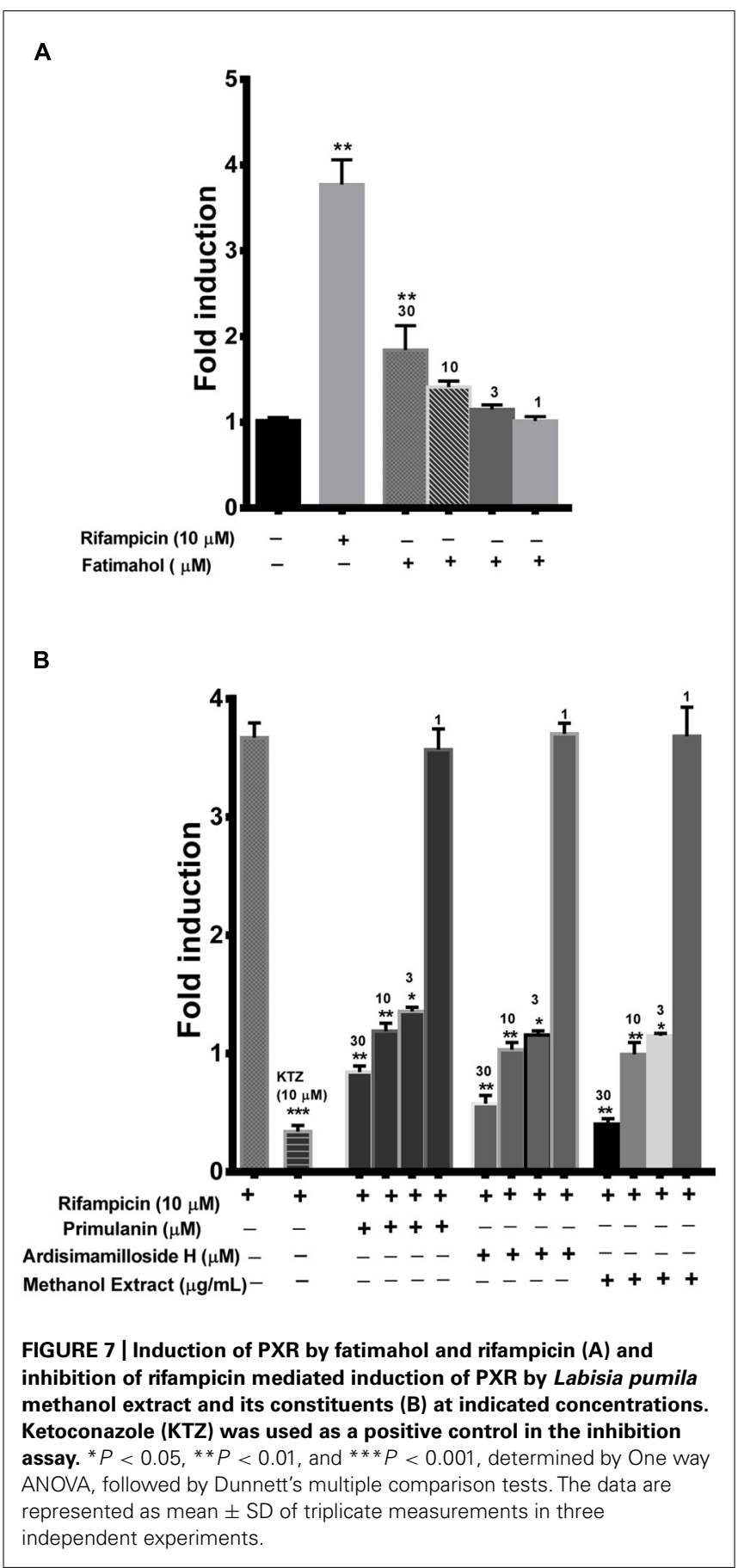

uptake was quantified in MDCK and hMDR1-MDCKII cells. The alkyl phenol compounds showed no increase in the uptake of calcein-AM in hMDR1-MDCKII cells. The methanolic extract and the two saponins, primulanin, and ardisimamilloside $\mathrm{H}$, increased the uptake of calcein-AM dose dependently with $\mathrm{EC}_{50}$ values of $28 \pm 1.4 \mu \mathrm{g} / \mathrm{mL}$ and $34 \pm 2.3$ and $42 \pm 3.5 \mu \mathrm{M}$, respectively, as shown in Figure 5. The effect is comparable to the effect of positive control, verapamil $\left(\mathrm{EC}_{50} 32 \pm 1.4 \mu \mathrm{M}\right)$ but significantly less potent than the effect of cyclosporin $\mathrm{A}$ $\left(\mathrm{EC}_{50} 8 \pm 1.2 \mu \mathrm{M}\right)$. The $\mathrm{P}_{\mathrm{app}}$ value of $\mathrm{LY}$ was in the range of
$1.1 \pm 0.8 \times 10^{-6} \mathrm{~cm} / \mathrm{s}$, which was similar to our previously published values (Manda etal., 2013). Additionally, the TEER measurements before and after experiments confirmed that the test compounds did not alter the monolayer integrity during the experiment.

The second probe used to determine the P-gp inhibition was radiolabelled digoxin $\left[{ }^{3} \mathrm{H}\right.$-digoxin $]$. Similar to the calcein-AM assay, the alkyl phenols had no effect on the basal to apical transport of digoxin in hMDR1-MDCKII cell monolayers, while the saponins and methanol extract showed strong inhibition. The $\mathrm{IC}_{50}$ values for primulanin, ardisimamilloside $\mathrm{H}$, and methanol extract were $6.4 \pm 2.3 \mu \mathrm{M}, 4.2 \pm 1.1 \mu \mathrm{M}$, and $8.5 \pm 2.4 \mu \mathrm{g} / \mathrm{mL}$, respectively, as compared to $1.1 \pm 0.8 \mu \mathrm{M}$ for cyclosporin $\mathrm{A}$ and $12 \pm 2.1 \mu \mathrm{M}$ for verapamil as shown in Figure 6. These results indicated that the extract of L. pumila and the two saponins inhibit P-gp strongly in terms of digoxin transport as compared to calceinAM transport suggesting that these saponins may bind to the similar binding site as for digoxin.

\section{PXR MODULATION}

Finally, we looked at the modulation of PXR activity by the extract and the constituents using a reporter gene assay in HepG2 cells. One of the alky phenols, fatimahol, significantly induced PXR activity (1.8-fold) at the highest tested concentration of $30 \mu \mathrm{M}$, while at lower concentration the effect was not significant Figure 7A. These results suggest that there is no effect on the PXR activation by KF extract or its constituents. The positive control, rifampicin $(10 \mu \mathrm{M})$ caused a fourfold induction in PXR activity which is in agreement with previous reports (Li and Chiang, 2006; Figure 7A). On the other hand, the methanolic extract $(3-30 \mu \mathrm{g} / \mathrm{mL})$ and the two saponins (primulanin and ardisimamilloside $\mathrm{H} ; 3-30 \mu \mathrm{M}$ ) dose dependently decreased rifampicin-induced PXR activity (Figure 7B). These results indicate that L. pumila and its constituents significantly modulate the activity of PXR and thereby could affect the downstream genes involved in PXR signaling. Additionally, no cytotoxicity was observed toward HepG2 cells with either KF methanolic extract or its constituents up to the highest tested concentration of $30 \mu \mathrm{g} / \mathrm{mL}$ or $30 \mu \mathrm{M}$ (data not shown) confirming that the inhibition of PXR as seen with methanolic extract and the two saponins is not due to the toxicity toward HepG2 cells.

\section{PREDICTION OF IN VIVO HDI FROM IN VITRO RESULTS}

The calculated \% yield and concentration per dose $(560 \mathrm{mg}$, single dose) was more for alkyl phenols compared to saponins from KF roots as shown in Table 2. Since the intestinal absorption or plasma concentrations are not known for the test compounds, we made an assumption that all of the compounds are completely absorbed ( $100 \%$ bioavailable) from the GI tract. Based on this, the predicted GI and plasma concentrations of the compounds were calculated as shown in Tables 2 and 3. The $\mathrm{IC}_{50}$ values from in vitro CYP inhibition assays suggest that the methanolic extract of KF is likely to cause in vivo inhibition of all the CYPs tested and thereby potentially causing HDI (Table 3). All alkyl phenols except fatimahol are predicted to have a likely in vivo effect toward CYP2C9 and 2C19 (Table 3). As show in Table 3, the extract or the compounds did 
Table 2 | Calculation of estimated extract per dose, GIT and plasma concentrations of KF methanol extract and its constituents.

\begin{tabular}{lllll}
\hline & Yield (W/W \%) & $\begin{array}{l}\text { Estimated concentration } \\
\text { per dose }(\mathbf{m g} / \mathbf{m L})\end{array}$ & $\begin{array}{l}\text { Estimated GIT } \\
\text { concentration }(\boldsymbol{\mu} \mathbf{g} / \mathbf{m L})\end{array}$ & $\begin{array}{c}\text { Estimated Plasma } \\
\mathbf{c o n c e n t r a t i o n}(\boldsymbol{\mu g} / \mathbf{m L})\end{array}$ \\
\hline Methanol Extract & 9.52 & 53.3 & 213 & 17.7 \\
Resorcinol & 1.21 & 6.72 & 27.1 & 2.2 \\
Belamcandol & 0.61 & 3.41 & 13.64 & 27.1 \\
Demethylbelamcandaquinone B & 1.21 & 6.77 & 0.20 & 2.25 \\
Fatimol & 0.009 & 0.05 & 0.31 & 0.016 \\
Primulanin & 0.014 & 0.07 & 0.047 & 0.026 \\
Ardisimamilloside H & 0.002 & 0.011 & 0.003 \\
\hline
\end{tabular}

All calculations were made based on the dose of $560 \mathrm{mg}$ per day of KF extract and its constituents.

Table 3 | Prediction of KF methanol extract and its constituents to cause herb drug interaction in vivo based on in vitro data.

\section{$\mathrm{IC}_{50}(\mu \mathrm{g} / \mathrm{mL}) \quad$ GIT concentration $(\mu \mathrm{g} / \mathrm{mL}) \quad$ Plasma concentration $(\mu \mathrm{g} / \mathrm{mL}) \quad$ Likelihood of causing HDI}

\section{CYP2D6}

Methanol extract 40

Resorcinol 28

Belamcandol 35

Demethylbelamcandaquinone B 22

Fatimahol

CYP1A2

Methanol extract 70

Resorcinol

Belamcandol

Demethylbelamcandaquinone B 50

Fatimahol

CYP3A4

Methanol extract

Resorcinol

Belamcandol

Demethylbelamcandaquinone B

Fatimahol

\section{CYP2C9}

Methanol extract

Resorcinol

Belamcandol

Demethylbelamcandaquinone B

Fatimahol

\section{CYP2C19}

Methanol extract

Resorcinol

Belamcandol

Demethylbelamcandaquinone B

Fatimahol
0.20

213

27.1

13.64

27.1

0.20

213

27.1

13.64

27.1

0.20

213

27.1

13.64

27.1

0.20

213

27.1

13.64

27.1

0.20
10.65

1.46

0.65

1.64

0.016

6.086

0.774

0.310

0.722

0.016

81.93

13.22

1.52

0.79

0.016

81.93

13.22

1.52

0.79

0.016

81.93

13.22

1.52

0.79

0.016 likely

Remote

unlikely

unlikely

unlikely

likely

Remote

unlikely

unlikely

unlikely

likely

likely

Remote

unlikely

unlikely

likely

likely

remote

likely

unlikely

likely

likely

likely

likely

unlikely 
not show any strong inhibition of CYP2D6 and CYP1A2. Accordingly, we did not further determine the time-dependent inhibition (TDI) of these two enzymes.

\section{DISCUSSION}

There is increasing evidence that the global use of herbal supplements for the treatment of a wide spectrum of ailments has been on the rise. Concurrently, there are more clinical cases of toxicity caused by concomitant administration of herbal supplements with conventional medicines (Colalto, 2010). This risk is mainly attributed due to the lack of research on the drug interaction potential of herbal medicines and their constituents. Such studies are needed to identify the potential herbs which may cause drug interactions and may help in reducing the risk of clinical toxicity (Chen et al., 2012). Furthermore, it is also of significant value to identify the constituents responsible for causing drug interactions. This will also enable us to identify the potential herbs which have similar chemical composition that may cause drug interactions. Based on the FDA guidelines related to the drug interaction, identifying compounds which interact with drug metabolizing enzymes and efflux transporters are of paramount importance since they play a major role in altering the pharmacokinetics and pharmacodynamics of majority of conventional drugs (Huang et al., 2008). Accordingly, the current study is focused on studying a widely used herb KF and some of its chemical constituents for the possibility of herb-drug interaction mediated by modulating the activities of CYPs, P-gp, and PXR using in vitro methods.

In the present study, the methanolic extract of KF and its constituents showed a moderate inhibition of CYP2D6 and 1A2 at higher concentrations. It is unlikely that most of these compounds will accumulate to such high physiological concentrations after oral intake. However, saponins isolated from Panax notoginseng were found to induce CYP1A2 with no inhibitory effect on the activity of other CYPs (Liu et al., 2012). In contrast, we observed a strong inhibition of CYP3A4, 2C19, and 2C9 by saponins and methanol extract of KF. In a previous study, crude extracts of KF have been reported to inhibit CYP2C isoforms; however, minimal effect was seen on CYP3A4 enzyme (Pan et al., 2012). These differences toward CYP3A4 activity may be attributed to the differences in the chemical composition of the extracts used in separate studies.

Time dependent inhibitors are categorized as mechanism based inhibitors. Such inhibitors are generally considered to have more profound clinical effects compared to reversible inhibitors as they form strong covalent bonds and thereby inactivate the CYPs (Riley et al., 2007; Venkatakrishnan et al., 2007). In order to find out if the methanolic extract or the constituents cause any TDI, the shift in $\mathrm{IC}_{50}$ for CYP3A4, 2C9, and 2C19 was calculated as result of preincubation of samples with recombinant enzymes, NADPH, and co-factors. Neither the methanol extract nor the alkyl phenolic compounds showed TDI of CYP2C9 and 2C19 suggesting that they interact reversibly with these two enzymes. In contrast, the pre-incubation of the methanol extract and all four alkyl phenols caused a significant shift in the $\mathrm{IC}_{50}$ value for CYP3A4. Specifically, the $\mathrm{IC}_{50}$ shift for 5-[10(Z)-pentadecenyl]resorcinol, fatimahol, and the extract was greater than positive control troleandomycin, which is considered to be a clinically relevant mechanism based inhibitor. Previous structural studies have shown that the phenolic moiety strongly binds to CYP3A4 enzyme causing a strong inhibition (Stresser and Kupfer, 1997) which may explain the prominent $\mathrm{IC}_{50}$ shift seen with the constituents of $\mathrm{KF}$ in our study. Moreover, the presence of phenolic hydroxyl group has been shown to lead to potent inhibition of CYP3A4 (Ho et al., 2001). Such a phenomenon may explain the high $\mathrm{IC}_{50}$ shift exhibited by 5 -[10(Z)-pentadecenyl] resorcinol which contains the phenolic hydroxyl group (Figure 1). The other alkyl phenols which did not have hydroxyl group showed comparatively weaker inhibition than 5-[10(Z)-pentadecenyl]resorcinol. This TDI of CYP3A4 could be due to either mechanism based inhibition (irreversible), or due to the generation of metabolites which may cause stronger inhibition of the enzyme. Further studies in liver microsomes are needed to clarify the exact mechanism of inhibition.

P-gp is known to contain multiple binding sites and consequently multiple probe substrates are recommended to determine if a compound is an inhibitor (Martin et al., 2000). We used calcein-AM and digoxin as our probe substrates as they are known to bind two different binding pockets of P-gp (Rautio etal., 2006). In the calcein-AM assay, the two saponins and the extract showed P-gp inhibition to a similar extent as verapamil but significantly lower than cyclosporin A. However, using digoxin as the substrate, much more potent inhibition of P-gp was seen. A similar trend was seen with verapamil which showed more potency in the digoxin assay, in accordance to previous report (Rautio et al., 2006). Our results indicate that the components of KF exhibit similar mechanism of P-gp inhibition as verapamil. Compounds which show $\mathrm{IC}_{50}$ values below $10 \mu \mathrm{M}$ in the digoxin transport assay are recommended for further evaluation in the in vivo system (Giacomini et al., 2010). Hence the extract and constituents of KF reported in this study would meet this criterion. Various saponin-containing herbs have been shown to be potent inhibitors of P-gp (Choi et al., 2003; Doligalska et al., 2011). However, the in vivo efficacy depends on additional factors such as the dose and the absorption/distribution profile of an inhibitor. KF extract and its constituents showed no significant activation of PXR activity except a moderate activation by fatimahol. However, this activation was only seen at higher concentrations, which would seem unlikely to cause in vivo effects. Similar to P-gp inhibition, the two saponins and methanol extract showed strong inhibition of rifampicinmediated induction of PXR activity. This may lead to a decrease in the expression of CYPs or efflux transporters. These effects were not due to the cytotoxicity of the KF methanol extract or its constituents as confirmed by MTS proliferation assay. Further studies are underway in our lab to determine the changes in expression of specific CYPs and efflux transporters using RTPCR analysis. Based on the clinical dose of KF capsules used by the general population, we predicted the ability of the constituents and extract to cause in vivo interactions. Alkyl phenolic compounds and methanolic extract are likely to cause HDI. However, it is highly unlikely that the whole amount of administered herbal preparation is absorbed and is available for interaction with the drug metabolizing CYPs. Further in vivo studies are warranted. 
In conclusion, this study demonstrated that the methanolic extract of KF and its constituents strongly inhibited (TDI) a major drug metabolizing enzyme CYP3A4, while a moderate reversible inhibition was seen with CYP2C9 and 2C19 with minimal effects on CYP 2D6 and 1A2. Inhibition of P-gp and PXR by the methanol extract could be attributed to the presence of saponins while inhibition of CYPs could be due to alkyl phenols. Taken together, concomitant use of L. pumila (KF) with conventional drugs could cause a possibility of drug-herb interaction. Further studies are warranted in this direction.

\section{ACKNOWLEDGMENTS}

The United States Department of Agriculture, Agricultural Research Service, Specific Cooperative Agreement No. 58-64081-603 and the United States Food and Drug Administration (FDA; Grant No. 1U01FD004246-3) are acknowledged for partial support of this work. The opinions expressed herein are attributable to the authors only, and do not represent the position of the FDA or any government agency. Holista Biotech Sdn Bhd, Malaysia, is also acknowledged for partial support and providing the authenticated plant material but Holista did not contribute to this report, nor does the work represent their opinions.

\section{REFERENCES}

Abdul Kadir, A., Nik Hussain, N. H., Wan Bebakar, W. M., Mohd, D. M., Wan Mohammad, W. M., Hassan, I. I., et al. (2012). The Effect of Labisia pumila var. alata on postmenopausal women: a pilot study. Evid. Based Complement. Alternat. Med. 2012, 216525. doi: 10.1155/2012/216525

Ali, Z., and Khan, I. A. (2011). Alkyl phenols and saponins from the roots of Labisia pumila (Kacip Fatimah). Phytochemistry 72, 2075-2080. doi: 10.1016/j.phytochem.2011.06.014

Alissa, E. M. (2014). Medicinal herbs and therapeutic drugs interactions. Ther. Drug Monit. 36, 413-422. doi: 10.1097/FTD.0000000000000035

Awortwe, C., Bouic, P. J., Masimirembwa, C. M., and Rosenkranz, B. (2014). Inhibition of major drug metabolizing CYPs by common herbal medicines used by HIV/AIDS patients in Africa- implications for herb- drug interactions. Drug Metab. Lett. 7, 83-95.

Chen, X. W., Serag, E. S., Sneed, K. B., Liang, J., Chew, H., Pan, S. Y., et al. (2011). Clinical herbal interactions with conventional drugs: from molecules to maladies. Curr. Med. Chem. 18, 4836-4850. doi: 10.2174/092986711797535317

Chen, X. W., Sneed, K. B., Pan, S. Y., Cao, C., Kanwar, J. R., Chew, H., et al. (2012). Herb-drug interactions and mechanistic and clinical considerations. Curr. Drug Metab. 13, 640-651. doi: 10.2174/1389200211209050640

Choi, C. H., Kang, G., and Min, Y. D. (2003). Reversal of P-glycoprotein-mediated multidrug resistance by protopanaxatriol ginsenosides from Korean red ginseng. Planta Med. 69, 235-240. doi: 10.1055/s-2003-38483

Colalto, C. (2010). Herbal interactions on absorption of drugs: mechanisms of action and clinical risk assessment. Pharmacol. Res. 62, 207-227. doi: 10.1016/j.phrs.2010.04.001

Crespi, C. L., Miller, V. P., and Penman, B. W. (1997). Microtiter plate assays for inhibition of human, drug-metabolizing cytochromes P450. Anal. Biochem. 248, 188-190. doi: 10.1006/abio.1997.2145

Doligalska, M., Jozwicka, K., Kiersnowska, M., Mroczek, A., Paczkowski, C., and Janiszowska, W. (2011). Triterpenoid saponins affect the function of P-glycoprotein and reduce the survival of the free-living stages of Heligmosomoides bakeri. Vet. Parasitol. 179, 144-151. doi: 10.1016/j.vetpar.2011. 01.053

Fathilah, S. N., Mohamed, N., Muhammad, N., Mohamed, I. N., Soelaiman, I. N., and Shuid, A. N. (2013). Labisia pumila regulates bone-related genes expressions in postmenopausal osteoporosis model. BMC Complement. Altern. Med. 13:217. doi: 10.1186/1472-6882-13-217

Giacomini, K. M., Huang, S. M., Tweedie, D. J., Benet, L. Z., Brouwer, K. L., Chu, X., et al. (2010). Membrane transporters in drug development. Nat. Rev. Drug Discov. 9, 215-236. doi: 10.1038/nrd3028
Goodwin, B., Hodgson, E., and Liddle, C. (1999). The orphan human pregnane X receptor mediates the transcriptional activation of CYP3A4 by rifampicin through a distal enhancer module. Mol. Pharmacol. 56, 1329-1339.

Ho, P. C., Saville, D. J., and Wanwimolruk, S. (2001). Inhibition of human CYP3A4 activity by grapefruit flavonoids, furanocoumarins and related compounds. $J$. Pharm. Pharm. Sci. 4, 217-227.

Huang, S. M., Strong, J. M., Zhang, L., Reynolds, K. S., Nallani, S., Temple, R., et al. (2008). New era in drug interaction evaluation: US Food and Drug Administration update on CYP enzymes, transporters, and the guidance process. J. Clin. Pharmacol. 48, 662-670. doi: 10.1177/0091270007312153

Karimi, E., Jaafar, H. Z., and Ahmad, S. (2013). Antifungal, anti-inflammatory and cytotoxicity activities of three varieties of Labisia pumila benth: from microwave obtained extracts. BMC Complement. Altern. Med. 13:20. doi: 10.1186/14726882-13-20

Lehmann, J. M., Mckee, D. D., Watson, M. A., Willson, T. M., Moore, J. T., and Kliewer, S. A. (1998). The human orphan nuclear receptor PXR is activated by compounds that regulate CYP3A4 gene expression and cause drug interactions. J. Clin. Invest. 102, 1016-1023. doi: 10.1172/jci3703

Li, T., and Chiang, J. Y. (2006). Rifampicin induction of CYP3A4 requires pregnane $\mathrm{X}$ receptor cross talk with hepatocyte nuclear factor 4alpha and coactivators, and suppression of small heterodimer partner gene expression. Drug Metab. Dispos. 34, 756-764. doi: 10.1124/dmd.105.007575

Liu, R., Qin, M., Hang, P., Liu, Y., Zhang, Z., and Liu, G. (2012). Effects of Panax notoginseng saponins on the activities of CYP1A2, CYP2C9, CYP2D6 and CYP3A4 in rats in vivo. Phytother. Res. 26, 1113-1118. doi: 10.1002/ptr.3688

Liu, X. L., Tee, H. W., and Go, M. L. (2008). Functionalized chalcones as selective inhibitors of P-glycoprotein and breast cancer resistance protein. Bioorg. Med. Chem. 16, 171-180. doi: 10.1016/j.bmc.2007.10.006

Manda, V. K., Avula, B., Ali, Z., Khan, I. A., Walker, L. A., and Khan, S. I. (2014). Evaluation of in vitro ADME properties of mitragynine, 7-hydroxymitragynine, and mitraphylline. Planta Med. 80, 568-576. doi: 10.1055/s-0034-1368444

Manda, V. K., Avula, B., Ali, Z., Wong, Y. H., Smillie, T. J., Khan, I. A., et al. (2013). Characterization of in vitro ADME properties of diosgenin and dioscin from Dioscorea villosa. Planta Med. 79, 1421-1428. doi: 10.1055/s-00331336521

Martin, C., Berridge, G., Higgins, C. F., Mistry, P., Charlton, P., and Callaghan, R. (2000). Communication between multiple drug binding sites on P-glycoprotein. Mol. Pharmacol. 58, 624-632. doi: 10.1124/mol.58.3.624

Nadia, M. E., Nazrun, A. S., Norazlina, M., Isa, N. M., Norliza, M., and Ima Nirwana, S. (2012). The anti-Inflammatory, phytoestrogenic, and antioxidative role of Labisia pumila in prevention of postmenopausal osteoporosis. Adv. Pharmacol. Sci. 2012, 706905. doi: 10.1155/2012/706905

Naritomi, Y., Teramura, Y., Terashita, S., and Kagayama, A. (2004). Utility of microtiter plate assays for human cytochrome P450 inhibition studies in drug discovery: application of simple method for detecting quasi-irreversible and irreversible inhibitors. Drug Metab. Pharmacokinet. 19, 55-61. doi: 10.2133/dmpk.19.55

Pan, Y., Tiong, K. H., Abd-Rashid, B. A., Ismail, Z., Ismail, R., Mak, J. W., et al. (2012). Inhibitory effects of cytochrome P450 enzymes CYP2C8, CYP2C9, CYP2C19 and CYP3A4 by Labisia pumila extracts. J. Ethnopharmacol. 143, 586-591. doi: 10.1016/j.jep.2012.07.024

Rautio, J., Humphreys, J. E., Webster, L. O., Balakrishnan, A., Keogh, J. P., Kunta, J. R., et al. (2006). In vitro p-glycoprotein inhibition assays for assessment of clinical drug interaction potential of new drug candidates: a recommendation for probe substrates. Drug Metab. Dispos. 34, 786-792. doi: 10.1124/dmd.105. 008615

Riley, R. J., Grime, K., and Weaver, R. (2007). Time-dependent CYP inhibition. Expert Opin. Drug Metab. Toxicol. 3, 51-66. doi: 10.1517/17425255.3.1.51

Sekiguchi, N., Higashida, A., Kato, M., Nabuchi, Y., Mitsui, T., Takanashi, K., et al. (2009). Prediction of drug-drug interactions based on time-dependent inhibition from high throughput screening of cytochrome P450 3A4 inhibition. Drug Metab. Pharmacokinet. 24, 500-510. doi: 10.2133/dmpk.24.500

Singh, G. D., Ganjoo, M., Youssouf, M. S., Koul, A., Sharma, R., Singh, S., etal. (2009). Sub-acute toxicity evaluation of an aqueous extract of Labisia pumila, a Malaysian herb. Food Chem. Toxicol. 47, 2661-2665. doi: 10.1016/j.fct.2009.07.031

Stresser, D. M., and Kupfer, D. (1997). Catalytic characteristics of CYP3A4: requirement for a phenolic function in ortho hydroxylation of estradiol 
and mono-O-demethylated methoxychlor. Biochemistry 36, 2203-2210. doi: 10.1021/bi962129k

Venkatakrishnan, K., Obach, R. S., and Rostami-Hodjegan, A. (2007). Mechanismbased inactivation of human cytochrome P450 enzymes: strategies for diagnosis and drug-drug interaction risk assessment. Xenobiotica 37, 1225-1256. doi: 10.1080/00498250701670945

Zhang, L., Zhang, Y. D., Zhao, P., and Huang, S. M. (2009). Predicting drug-drug interactions: an FDA perspective. AAPS J. 11, 300-306. doi: 10.1208/s12248-0099106-3

Conflict of Interest Statement: The authors declare that the research was conducted in the absence of any commercial or financial relationships that could be construed as a potential conflict of interest.
Received: 07 May 2014; accepted: 11 July 2014; published online: 08 August 2014. Citation: Manda VK, Dale OR, Awortwe C, Ali Z, Khan IA, Walker LA and Khan SI (2014) Evaluation of drug interaction potential of Labisia pumila (Kacip Fatimah) and its constituents. Front. Pharmacol. 5:178. doi: 10.3389/fphar.2014.00178

This article was submitted to Pharmaceutical Medicine and Outcomes Research, a section of the journal Frontiers in Pharmacology.

Copyright (C) 2014 Manda, Dale, Awortwe, Ali, Khan, Walker and Khan. This is an open-access article distributed under the terms of the Creative Commons Attribution License (CC BY). The use, distribution or reproduction in other forums is permitted, provided the original author(s) or licensor are credited and that the original publication in this journal is cited, in accordance with accepted academic practice. No use, distribution or reproduction is permitted which does not comply with these terms. 